\section{Um estudo preliminar sobre a prosódia de construções com tópico e foco no português paulista*}

A preliminary study on prosody of topic and focus constructions in Portuguese of São Paulo

Cynthia Tomoe YANO (USP) ctyano@gmail.com

Flaviane Romani FERNANDES-SVARTMAN (USP) flavianesvartman@usp.br

Recebido em: 03 de out. de 2019. Aceito em: 30 de dez. de 2019.

*O presente trabalho foi realizado com apoio do Conselho Nacional de Desenvolvimento Científico e Tecnológico (CNPq) - Códigos de Financiamento 313103/20186 e 437021/2018-1 - concedido ao segundo autor.
YANO, Cynthia Tomoe; FERNANDESSVARTMAN, Flaviane Romani. Um estudo preliminar sobre a prosódia de construções com tópico e foco no português paulista. Entrepalavras, Fortaleza, v. 10, n. 1, p. 256-282, janabr/2020. DOI: $10.22168 / 2237-6321-$ 11724 .

Resumo: Este trabalho objetiva analisar as estratégias prosódicas relacionadas ao fraseamento prosódico e à configuração tonal associados à marcação de tópico e foco em sentenças declarativas do português brasileiro (doravante, PB), com enfoque no dialeto falado na cidade de São Paulo, ainda não descrito nesse sentido. Através da análise de dados produzidos por falantes de São Paulo, observou-se que as estratégias empregadas para a marcação prosódica de foco e tópico se assemelham às já descritas em estudos anteriores para outras variedades do PB (MORAES; ORSINI, 2003; ORSINI, 2005; FERNANDES, 2007; TRUCKENBRODT et al., 2009; FROTA et al., 2015; entre outros). Isto é, parece haver uma distinção entre os dois tipos de construção, uma vez que tópicos, independentemente da sua posição na sentença, tendem a formar sintagmas entoacionais(I)independentes, apresentando uma pausa e um tom de fronteira baixo ou alto na sua fronteira direita. Porém, expressões focalizadas não necessariamente formam um I independente, pois, em posição inicial, pode também ocorrer um acento frasal baixo associado à direita do sintagma fonológico $(\varphi)$ que contém a expressão focalizada e, portanto, tal domínio está contido no mesmo I que contém o restante da sentença.

Palavras-chave: Tópico. Foco. Português brasileiro. 
Abstract: This paper aims at analyzing prosodic strategies related to the prosodic phrasing and the tonal configuration associated with topic and focus constructions in declarative sentences of Brazilian Portuguese (BP), focusing on the dialect spoken in the city of São Paulo, not yet described in that sense. From the analysis of data produced by speakers from São Paulo, it was noted that the strategies employed to mark focus and topic are similar to the ones described in previous studies for other dialects of BP (MORAES; ORSINI, 2003; ORSINI, 2005; FERNANDES, 2007; TRUCKENBRODT et al., 2009; FROTA et al., 2015; among others). That is, there seems to be a distinction between the two types of construction, since topics, regardless of their position in the sentence, tend to form independent intonational phrases (I), presenting a pause and a low or high boundary tone at its right border. However, focused expressions do not necessarily form an independent I, since, in initial position, a low phrasal accent may be associated with the right edge of the phonological phrase $(\varphi)$ that contains the focused expression, and therefore, this domain is contained in the same I that includes the rest of the sentence.

Keywords: Topic. Focus. Brazilian Portuguese.

\section{Introdução}

Este trabalho tem como objetivo investigar as estratégias prosódicas relativas ao fraseamento prosódico e à configuração tonal do contorno entoacional, usadas pelos falantes para marcar tópico e foco em sentenças declarativas do $\mathrm{PB}$. Tem-se como enfoque principal o dialeto falado na cidade de São Paulo, ainda não descrito nesse sentido nos estudos sobre a prosódia do português. Além disso, também é feita uma análise comparativa com outras variedades do PB e do PE, descritas em trabalhos anteriores (MORAES; ORSINI, 2003; ORSINI, 2005; FERNANDES, 2007; TRUCKENBRODT et al., 2009; FROTA et al., 2015; entre outros).

Tendo como base esses estudos prévios, trabalha-se com a hipótese de que, no português, foco e tópico se comportam de maneira distinta em relação ao fraseamento prosódico. Os resultados obtidos da análise de um corpus de dados de fala de informantes da cidade de São Paulo vão no sentido dessa hipótese, sendo a principal distinção na estrutura prosódica de tópico e foco o fato de o primeiro, a despeito da sua posição na sentença, sempre formar um sintagma entoacional (I) ${ }^{1}$ independente. Em construções com tópico, tanto tópicos-sujeito em posição inicial, quanto tópicos deslocados à esquerda tendem a formar um I independente do resto da sentença, sendo a fronteira direita desse sintagma marcada por pausa e um tom de fronteira ${ }^{2}$ alto

\footnotetext{
${ }^{1}$ Sobre o sintagma entoacional (I) em português, conferir a fundamentação teórica deste artigo.

${ }^{2}$ Sobre tom de fronteira, conferir a fundamentação teórica deste artigo.
} 
V. 10 (1)

256-282

jan-abr

2020

ou baixo. Porém, em construções com foco, a expressão focalizada não parece necessariamente formar um I independente, pois, em início de sentença, pode ocorrer um tom de fronteira alto ou baixo associado à direita do I formado unicamente pela expressão focalizada, ou um acento frasal 3 baixo associado à direita do sintagma fonológico $(\varphi)^{4}$ que contém a expressão focalizada, a qual, portanto, está contida no mesmo I do restante da sentença.

O trabalho se organiza da seguinte forma: na próxima seção, será apresentada a fundamentação teórica em que se baseia a análise prosódica dos dados, bem como definições sobre tópico e foco e descrições de estudos anteriores sobre as características prosódicas desses tipos de construções para variedades do PB e do português europeu (doravante, PE). Em seguida, serão descritos o corpus e a metodologia adotada na segmentação, anotação e análise prosódica dos dados. Logo após, serão apresentadas a descrição e a discussão dos resultados obtidos, bem como a comparação desses resultados com os já descritos na literatura para outras variedades do português. E, por fim, serão expostas as considerações finais sobre o trabalho.

\section{Fundamentação teórica}

\section{Fonologia Prosódica}

A Fonologia Prosódica é um modelo teórico que pressupõe que o fluxo de fala se organiza de forma hierarquizada, em constituintes fonológicos que formam contextos ou domínios para a aplicação de regras fonológicas, além de outros fenômenos fonético-fonológicos. Esses constituintes se organizam de modo que cada unidade constitui uma unidade maior, que a domina imediatamente, ou seja: os segmentos formam sílabas $(\sigma)$, as sílabas formam Pés $(\Sigma)$, os pés formam as Palavras Prosódicas $(\omega)$, as palavras prosódicas formam o Sintagma Fonológico $(\varphi)$, os sintagmas fonológicos formam o Sintagma Entoacional (I) e, por fim, os sintagmas entoacionais formam o Enunciado Fonológico (U). A operação de regras fonológicas no interior e na juntura de alguns domínios é a evidência para a proposição desses domínios (NESPOR; VOGEL, 1986, 2007).

\footnotetext{
3 Sobre acento frasal, conferir a fundamentação teórica deste artigo.

4 Sobre o sintagma fonológico $(\varphi)$ em português, conferir a fundamentação teórica deste artigo.
} 
Além disso, embora o componente fonológico funcione em interação com os demais componentes da gramática, nem sempre há isomorfismo entre eles, ou seja, pode não haver uma correspondência exata entre a estrutura fonológica e a estrutura sintática ou morfológica. Isso porque as regras fonológicas se aplicam em domínios que não são estritamente os estabelecidos pela estrutura morfossintática. (SELKIRK, 1984, 1986; NESPOR; VOGEL, 1986, 2007).

Para a análise aqui apresentada, são considerados os domínios da palavra prosódica $(\omega)$, do sintagma fonológico $(\varphi)$ e do sintagma entoacional (I), que são os domínios relevantes para a descrição da associação de eventos tonais ao contorno entoacional de sentenças com foco e tópico e ao contorno entoacional de sentenças declarativas neutras no português (FROTA, 2000, 2014; TENANI, 2002; FERNANDES, 2007; SERRA, 2009; BARROS, 2014; FROTA et al., 2015a).

Sobre a palavra prosódica em português, adota-se a concepção de palavra prosódica mínima de Vigário (2003, p. 263), segundo a qual, uma palavra prosódica mínima deve conter um e somente um acento primário.

Sobre o sintagma fonológico, adota-se o algoritmo de formação proposto por Nespor e Vogel (1986) e adaptado por Frota (2000, p. 56) para o português:

Phonological Phrase $(\varphi)$ Formation

a. $\varphi$ Domain: a lexical head $\mathrm{X}$ and all elements on its non recursive side which are still within the maximal projection of X.

b. $\varphi$ Restructuring: optional, obligatory or prohibited inclusion of a branching or non-branching $\varphi$ which is the first complement of $\mathrm{X}$ into the $\varphi$ that contains $\mathrm{X}$.

Quanto ao sintagma entoacional, adota-se também o algoritmo de formação prosposto por Nespor e Vogel (1986) e adaptado por Frota (2000, p. 57) para o português:

Intonational Phrase (I) formation

a. I Domain: (i) all the fs in a string that is not structurally attached to the sentence tree (i.e. parenthetical expression, tag questions, vocatives, etc); (ii) any remaining sequence of adjacent fs in a root sentence; (iii) the domain of an intonation contour, whose boundaries coincide with the positions in which grammar-related pauses may be introduced in an utterance.

b. I Restructuring: (i) restructuring of one basic I into shorter Is, or (ii) restructuring of basic Is into a larger I. Factors that play a role in I restructuring: length of the constituents, rate of speech, and style interact with syntactic and semantic restrictions. 
V. 10 (1)

256-282

jan-abr

2020
Fonologia Entoacional

O modelo da Fonologia Entoacional (PIERREHUMBERT, 1980; BECKMAN; PIERREHUMBERT, 1988; LADD, 1996, 2008; entre outros) pressupõe que a entoação possui uma organização fonológica, que se constitui em contornos entoacionais e está em relação com a estrutura prosódica. Tais contornos são descritos como uma sequência de eventos tonais alocados em pontos específicos na cadeia segmental, que podem ser constituídos por tons altos - H (high) - ou baixos - L (low). Esses tons podem formar os acentos tonais e os tons relacionados à fronteira. Os acentos tonais são associados à sílaba tônica, marcados com um asterisco (*), e se distinguem em dois tipos: simples ou monotonais, compostos por apenas um tom ( $\left.\mathrm{L}^{*}, \mathrm{H}^{*}\right)$, ou complexos ou bitonais, compostos por dois tons $\left(\mathrm{L}^{*}+\mathrm{H}, \mathrm{L}+\mathrm{H}^{*}, \mathrm{H}^{*}+\mathrm{L}, \mathrm{H}+\mathrm{L}^{*}\right)$. Os tons relacionados à fronteira podem estar associados a fronteiras de domínios prosódicos mais altos (como I e U), sendo denominados "tons de fronteira" e seguidos pelo símbolo "\%", ou de domínios prosódicos mais baixos (como $\varphi$ ), sendo denominados "acentos frasais" e seguidos pelo símbolo "_". Os tons relacionados à fronteira podem, em português, também ser simples (altos ou baixos: H\%, H-, L\%, L-) ou complexos (ascendentes (LH\%, LH-) ou descendentes (HL\%, HL-)). (cf. FROTA et al., 2015a; FROTA et al., 2015b)

Estudos prévios sobre o fraseamento prosódico e a configuração entoacional de construções com tópico e foco em variedades do PB e do PE

Primeiramente, com relação às construções com tópico, neste trabalho, serão analisadas as construções com tópico-sujeito e topicalização. De acordo com Moraes e Orsini (2003) e Orsini (2005), no primeiro caso, por um processo de gramaticalização, o tópico éreanalisado como sujeito e, com isso, porta traços de ambas as categorias, de sujeito e de tópico, as quais, em construções de sujeito-predicado e tópicocomentário, distinguem-se pela inserção de pausa mais frequente após tópicos-sujeito. Já a topicalização se caracteriza pela presença de uma categoria vazia no comentário, que se refere ao elemento topicalizado em uma posição externa na sentença. Nos respectivos exemplos 1 e 2, abaixo, os tópicos dos dois tipos estão indicados em itálico.

1. O primeiro emprego tinha muitas regalias.

2. Óculos escuros eu uso 
Sobre as estratégias de marcação prosódica de tópico no PB, Moraes e Orsini (2003) mostram que, na variedade carioca, tanto nas construções com tópico-sujeito, contendo um $\varphi$ ramificado ("o primeiro emprego" - exemplo 3) em posição inicial, como nas com tópico deslocado à esquerda também contendo um $\varphi$ ramificado ("o primeiro emprego" - exemplo 4), ocorre, com maior frequência, o contorno $\mathrm{H}^{*}+\mathrm{L} \mathrm{H} \mathrm{H}^{*} \mathrm{H} \%$ associado a essas construções e a inserção de pausa após elas mesmas.

3. O primeiro emprego tinha muitas regalias.

4. O primeiro emprego, ele é o mais marcante.

Em um estudo posterior, porém, Orsini (2005), também para a variedade carioca do $\mathrm{PB}$, apresenta uma análise um pouco distinta, conforme a qual, em construções com o tópico in situ inicial, que contém um $\varphi$ ramificado (exemplo de Orsini (2005): "todos aniversário(s)" - ver exemplo em 5.), o contorno mais frequente é $\mathrm{H}^{*} \mathrm{~L}+\mathrm{H}^{*} \mathrm{H} \%$, semelhante ao contorno do sujeito de construções sujeito/predicado, com a diferença de haver tom de fronteira alto (H\%) e pausa após um tópico-sujeito. Em construções com tópico deslocado à esquerda, contendo um constituinte ramificado (exemplo de Orsini (2005): "banana frita" - ver exemplo em 6.), predomina o contorno acentual $\mathrm{H}^{*} \mathrm{~L}+\mathrm{H}^{*} \mathrm{~L} \%$, com a presença de pausa após o elemento topicalizado.

5. todos aniversário(s) tem festa.

6. banana frita de vez em quando a gente faz.

Por sua vez, Serra (2009), buscando analisar o fraseamento prosódico do PB e com base em dados de fala espontânea e de leitura do dialeto carioca, também notou que tópicos tendem a formar Is independentes e que a inserção de pausa é uma das estratégias mais recorrentes na marcação e para a percepção das fronteiras desse domínio prosódico.

Quanto ao fraseamento prosódico das construções de tópico no PE, Frota (2000, 2014) mostra que, na variedade standard (falada em Lisboa), os tópicos formam Is independentes, sendo mais frequentes o contorno $\mathrm{L}^{*}+\mathrm{H} \mathrm{H} \%$ ou $\mathrm{H}+\mathrm{L}^{*} \mathrm{~L} \%$ para tópicos em posição inicial e o contorno $\mathrm{H}+\mathrm{L} * \mathrm{H} \% / \mathrm{L} \%$ para tópicos em posição final. 
V. 10 (1)

256-282

jan-abr

2020

Indo na mesma direção, Barros (2014), analisando o fraseamento de construções de tópico, ilustrados nos exemplos 7-11 abaixo nas variedades faladas nas regiões do Porto e de Évora, notou que, no Porto, em posição inicial, os tópicos deslocados tendem a ser marcados pelo contorno $\mathrm{L}^{*}(+\mathrm{H})^{5} \mathrm{H} \%$ e os tópicos in situ, pelo contorno $(\mathrm{H}+) \mathrm{L}^{*} \mathrm{H} \%$. Já em posição final, tanto os tópicos deslocados como os in situ tendem a ser marcados pelo contorno $(\mathrm{H}+) \mathrm{L}^{*} \mathrm{~L} \%$, semelhante ao contorno característico de sentenças declarativas neutras. Todavia, ao observar os constituintes precedentes aos tópicos finais, a autora notou que os tópicos in situ são mais frequentemente precedidos por um tom de fronteira $\mathrm{H} \%$, enquanto os tópicos deslocados, por um tom de fronteira baixo L\%, nos dados do Porto. Já em Évora, em posição inicial, os tópicos in situ e deslocados tendem a ser marcados pelo contorno $(\mathrm{H}+) \mathrm{L}^{*} \mathrm{H} \% / \mathrm{L} \%$, embora - nos casos com tópicos longos deslocados à esquerda - seja predominante o contorno ascendente $\mathrm{L}+\mathrm{H} * \mathrm{H} \%$. Em posição final, os tópicos in situ e deslocados tendem a ser marcados pelo contorno $(\mathrm{H}+) \mathrm{L}^{*}$, distinguindo-se pelo tipo de tom de fronteira dos constituintes precedentes: $\mathrm{H} \%$ para os tópicos in situ e L\% para os tópicos deslocados. Ademais, a autora notou que, na variedade do Porto, a inserção de pausa parece distinguir tópicos deslocados de tópicos in situ, sendo mais marginal em tópicos in situ, sobretudo em posição inicial, e mais recorrente nas fronteiras à esquerda ou à direita de tópicos deslocados. Ao contrário, na variedade de Évora, a inserção de pausa é menos frequente em construções com tópicos deslocados, sobretudo os com deslocamento à direita, e mais frequente antes ou depois de tópicos in situ.

7. As angolanas, ofereceram especiarias aos jornalistas. (tópico in situ inicial)

8. As angolanas ofereceram especiarias, aos jornalistas. (tópico in situ final)

9. As rosas, as alunas ofereceram ao monitor. (tópico curto deslocado à esquerda)

10.Aos jornalistas, as angolanas ofereceram especiarias. (tópico longo deslocado à esquerda)

11. Ofereceram especiarias aos jornalistas, as angolanas. (tópico deslocado à direita)

${ }_{5}$ De acordo com a notação adotada pela autora, os parênteses são utilizados para indicar que o tom alto $\mathrm{H}$ dos contornos $\mathrm{L}^{*}+\mathrm{H}$ e $\mathrm{H}+\mathrm{L}^{*}$ pode ou não ser realizado. 
A respeito das construções com foco analisadas, elas dizem respeito aos focos dos tipos contrastivo e informacional. Segundo Fernandes (2006, 2007), o foco contrastivo se define por ser utilizado para corrigir ou negar uma pressuposição dada em um enunciado prévio, de forma explícita ou implícita, e por carregar informação nova (exemplo em 12). Já o foco informacional é usado quando a expressão focalizada apenas carrega informação nova e é parte do enunciadoresposta de uma pergunta feita antes (exemplo em 13). Nos respectivos exemplos em 12 e 13, abaixo, as expressões focalizadas estão indicadas em itálico.

12. O Pedro comprou livros?

a. Não, o João comprou livros.

13. Quem comprou livros?

b. O João comprou livros.

Particularmente quanto às construções com foco informacional no PB, Fernandes (2007) observou que, no dialeto paulista do PB falado em Campinas, em construções com o sujeito focalizado em posição inicial, tende a ocorrer o contorno $\mathrm{L}^{*}+\mathrm{H}$ associado ao elemento focalizado, similar ao encontrado para o sujeito das sentenças declarativas neutras, ou o contorno $\mathrm{H}^{*}+\mathrm{L}$, além da possibilidade de haver um acento frasal associado à fronteira direita de $\varphi$ que contém o sujeito focalizado, quando o contorno associado ao elemento focalizado é $\mathrm{L}^{*}+\mathrm{H}$. Além disso, nesse mesmo tipo de sentença, a autora notou ausência de associação de acentos tonais a palavras prosódicas intermediárias (entre o elemento focalizado e a última palavra prosódica ${ }^{6}(\omega)$ cabeça de I) e, ao final da sentença, o contorno nuclear $\mathrm{H}+\mathrm{L} * \mathrm{~L} \%$ ou apenas um tom de fronteira $\mathrm{L} \%$ associado à fronteira final de I.

Por sua vez, Truckenbrodt et al. (2009), também analisando o foco, bem como outras construções, na variedade do PB falada em Campinas, não observaram uma escolha de contorno consistente entre os dados com o sujeito focalizado em posição inicial, podendo ocorrer tanto o contorno $\mathrm{H}^{*}+\mathrm{L} \mathrm{L} \%$ como $\mathrm{L}^{*}$, seguido por um acento frasal $\mathrm{H}-$ associado à fronteira direita do $\varphi$ que contém o sujeito focalizado. E para foco em posição final, os autores encontraram o contorno $\mathrm{H}+\mathrm{L}^{*}$ $\mathrm{L} \%$.

${ }^{6}$ Sobre a palavra prosódica em português, conferir a fundamentação teórica deste trabalho. 
V. 10 (1)

256-282

jan-abr

2020

De acordo com Frota et al. (2015a), nas variedades faladas nas regiões da Bahia, Minas Gerais, São Paulo e Rio Grande do Sul, construções com foco informacional, em geral, se caracterizam por um contorno descendente $\mathrm{H}+\mathrm{L} * \mathrm{~L} \%$ ao final do contorno da sentença, semelhante ao de sentenças declarativas neutras. Já em construções com foco contrastivo, em posição inicial, os autores observaram, nas variedades baiana, mineira e paulista, o contorno $\mathrm{L}^{*}+\mathrm{H}$ associado à sílaba tônica da expressão focalizada e, na variedade gaúcha, o contorno $\mathrm{L}+\mathrm{H}^{*}$. Após esses acentos tonais, não se encontrou, em nenhuma das variedades, a ocorrência de acento frasal ou tom de fronteira associado à fronteira direita da expressão focalizada. E, em posição final, se encontram os mesmos tipos de contornos, com a diferença de que, nas variedades paulista, mineira e baiana, ocorre um tom de fronteira L\% ao final do contorno da sentença e, na variedade gaúcha, um tom de fronteira alto com downstep", indicado por "!", ! H\%.

Sobre as construções com foco no PE, Frota (1997, 2000, 2002), Vigário (1998) e Fernandes (2007) afirmam que, na variedade de Lisboa, predomina o contorno $\mathrm{H}^{*}+\mathrm{L}$ associado à sílaba tônica da expressão focalizada e, ao final do contorno da sentença que contém essa expressão, assim como observado para o PB, pode haver um contorno $\mathrm{H}+\mathrm{L}^{*} \mathrm{~L} \%$ ou apenas um tom de fronteira $\mathrm{L} \%$. Já em construções com sujeito focalizado em posição final, Fernandes encontrou, com maior frequência, o contorno $\mathrm{H}+\mathrm{L} * \mathrm{~L} \%$, quando o sujeito não é ramificado, composto por uma $\omega$, ou $\mathrm{L}^{*}+\mathrm{H} \mathrm{H}+\mathrm{L} * \mathrm{~L} \%$, quando o sujeito é ramificado, composto por mais de uma $\omega$ (duas $\omega s$ nos dados da autora).

Segundo Frota et al. (2015a), nas variedades standard, do Porto, do Alentejo e de Algarve do PE, construções com foco informacional em posição final de sentença são, em geral, marcadas por um contorno nuclear similar ao de declarativas neutras, isto é, um contorno descendente $\mathrm{H}+\mathrm{L} * \mathrm{~L} \%$. As exceções se dão na variedade da região do Alentejo, em que predomina, para as construções com foco informacional em posição final de sentença, a ocorrência apenas de um acento tonal baixo $\mathrm{L}^{*}$, seguido de tom de fronteira L\%, sendo marginal a ocorrência do contorno descendente, e na variedade do Porto, em que ambos os tipos de contorno podem ocorrer, com distribuição similar para o já referido tipo de construção. Já sobre o foco de tipo contrastivo, tanto em posição inicial como final, os autores observaram, em todas as variedades, o contorno $\mathrm{H}^{*}+\mathrm{L}$ associado à sílaba tônica da expressão focalizada, seguido por tom de fronteira L\%.

7 Segundo Ladd (2008), downstep se caracteriza como um rebaixamento do pico acentual de Fo, em relação ao pico precedente, em determinados pontos da sentença, causando um declínio no contorno da sentença. 


\section{Corpus e metodologia}

O conjunto de dados utilizado para a análise corresponde a um sub-corpus proveniente do corpus do projeto InAPoP - Interactive Atlas of the Prosody of Portuguese (FROTA, 2012-2015), no âmbito do qual este trabalho foi desenvolvido ${ }^{8}$. Quanto à coleta dos dados ${ }^{9}$, foi aplicada a tarefa de Reading Task ${ }^{10}$, em que é apresentado um tipo de contexto discursivo e, na sequência, é feita uma pergunta. Os contextos são construídos de acordo com o tipo de dado que se busca obter com a resposta do informante, como, por exemplo, o contexto abaixo, com o qual se busca obter a produção de tópico.

a. [Contexto: Entre as oferendas, tinha vários tipos de flores.

Você sabe o que aconteceu com as rosas?]

As rosas, os alunos ofereceram ao monitor.

O corpus utilizado é composto por dados de fala de 3 informantes da cidade de São Paulo (CS, EF e LC), de mesmo grau de escolaridade (nível superior completo), sexo (feminino) e faixa etária (entre 20 e 40 anos), e constituído por 5 sentenças com tópico, 8 sentenças com foco e 5 sentenças declarativas neutras, para fins comparativos. Para cada enunciado, foi solicitado que cada informante o repetisse 2 vezes. Entretanto, cabe informar que, nos dados do informante CS, há 3 casos em que não houve repetição - um dado de tópico, um dado de foco e um dado de sentença neutra. Portanto, o total de dados analisados é de 105 sentenças: ( 5 sentenças com tópico +8 sentenças com foco +5 sentenças neutras) x 3 informantes x 2 repetições -3 casos de sentenças não repetidas.

\footnotetext{
8 O projeto Interactive Atlas of the Prosody of Portuguese (InAPoP) (FCT, PTDC/ CLELIN/119787/2010), coordenado pela Profa. Dra. Sónia Frota e desenvolvido na Universidade de Lisboa, tem como principal objetivo a construção de um Atlas Interativo da Prosódia do Português, acessado livremente por uma plataforma online (www.fl.ul. pt/LaboratorioFonetica/InAPoP), que contemple a variação prosódica, entoacional e rítmica do português, incluindo a cobertura completa do português europeu quanto a estes três aspectos, contando ainda com variedades do PB ao longo da costa do Atlântico, assim como variedades do português falado na África.

9 É importante esclarecer que os dados foram extraídos diretamente do banco de dados do projeto InAPoP. Portanto, a coleta foi feita por outro pesquisador e não pelos autores deste artigo.

${ }^{10}$ Para maiores detalhes sobre as metodologias de coleta de dados aplicadas no âmbito do projeto InAPoP, acessar o site http://labfon.letras.ulisboa.pt/InAPoP/ methodology. html.
} 
V. 10 (1)

256-282

jan-abr 2020

Sobre os tipos de sentenças com foco e tópico, foram analisadas as construções: a) com tópico in situ inicial; b) com tópico in situ final; c) com tópico deslocado à esquerda; d) com tópico deslocado à direita; e) com foco inicial informativo; f) com foco inicial contrastivo; g) com foco final contrastivo em constituinte não-ramificado; h) com foco final contrastivo em elemento não-cabeça de constituinte ramificado. Os dados analisados, com os seus respectivos contextos de elicitação, são exemplificados abaixo nos itens a-h. As expressões topicalizadas ou focalizadas aparecem sublinhadas.

\section{a. Tópico in situ inicial}

[Contexto: Angolanas e moçambicanas exiladas em Portugal resolveram trazer aos jornalistas presentes provenientes dos seus países. Quanto às moçambicanas, trouxeram plantas exóticas.] As angolanas, ofereceram especiarias aos jornalistas.

b. Tópico in situ final

[Contexto: Jovens africanas estudando em Portugal ofereceram ontem os seus presentes aos jornalistas portugueses.] As angolanas ofereceram especiarias, aos jornalistas.

c. Tópico deslocado à esquerda

[Contexto: Entre as oferendas, tinha vários tipos de flores. Você sabe o que aconteceu com as rosas?] As rosas, as alunas ofereceram ao monitor.

\section{d. Tópico deslocado à direita}

[Contexto: Você sabe o que é que as angolanas fizeram?] Ofereceram especiarias aos jornalistas, as angolanas.

e. Foco inicial informativo

[Contexto: Quem ofereceu especiarias aos jornalistas?] As angolanas ofereceram especiarias aos jornalistas. 


\section{f. Foco inicial contrastivo}

[Contexto: Naquele filme é o vilão que anda de porsche?] o galã anda de porsche.

g. Foco final contrastivo em constituinte não-ramificado

[Contexto: Foi aos artistas que as angolanas ofereceram especiarias?]

As angolanas ofereceram especiarias aos jornalistas.

h. Foco final contrastivo em elemento não-cabeça de constituinte ramificado

[Contexto: Foi uma tarde âmbar que o pintor retratou?]

O pintor retratou uma manhã âmbar.

A respeito da análise prosódica dos dados, utilizou-se a ferramenta computacional de análise de fala Praat ${ }^{11}$ (BOERSMA; WEENINK, 2017), na qual foram realizadas a segmentação dos enunciados em palavras, a delimitação das pausas (anotadas como <sil.>, "silêncio") e a transcrição dos eventos tonais dos contornos entoacionais associados às sentenças, com base na percepção auditiva e na análise acústica, e de acordo com o modelo da Fonologia Entoacional (PIERREHUMBERT, 1980; BECKMAN; PIERREHUMBERT, 1988; LADD, 1996; entre outros; e sobre a aplicação desse modelo em PB, conferir FROTA; VIGÁRIO, 2000; TENANI, 2002; FERNANDES, 2007; TRUCKENBRODT et al., 2009; FROTA et al., 2015a; entre outros).

\section{Resultados}

Tópico

Quanto aos dados com tópico, o quadro 1 mostra os tipos de configurações tonais encontrados associados às expressões topicalizadas, bem como os seus valores absolutos e percentuais de ocorrência. Os dados aparecem agrupados no quadro referido de acordo com a posição do tópico na sentença.

\footnotetext{
${ }^{11}$ Para maiores detalhes sobre a ferramenta Praat e como utilizá-la, acessar os sites: www.fon.hum.uva.nl/praat e www.usp.br/gmhp/soft/praat.pdf.
} 
V. $10(1)$

256-282

jan-abr 2020

Quadro 1 - Ocorrências das configurações tonais associadas aos diferentes tipos de elementos topicalizados

\begin{tabular}{|c|c|c|c|}
\hline Posição do tópico (T) & Configuração tonal & $\begin{array}{l}\text { Número de } \\
\text { ocorrências }\end{array}$ & $\begin{array}{c}\text { \% de } \\
\text { ocorrência }\end{array}$ \\
\hline \multirow{4}{*}{ T in situ inicial } & $\mathrm{L}^{*}+\mathrm{H}$ & 2 & $33,3 \%$ \\
\hline & $\mathrm{L}^{*}+\mathrm{H} \mathrm{H} \%$ & 2 & $33,3 \%$ \\
\hline & $\mathrm{H}^{*}+\mathrm{L}^{12}$ & 1 & $16,6 \%$ \\
\hline & $\mathrm{H} \% \mathrm{H}^{*}+\mathrm{L}$ & 1 & $16,6 \%$ \\
\hline $\mathrm{T}$ in situ final & $\mathrm{H}+\mathrm{L} * \mathrm{~L} \%$ & 6 & $100 \%$ \\
\hline \multirow{5}{*}{$\mathrm{T}$ deslocado à esquerda ${ }^{13}$} & $\mathrm{H}^{*}+\mathrm{L} \mathrm{L} \%$ & 4 & $33,3 \%$ \\
\hline & $\mathrm{H}^{*}+\mathrm{L}$ & 3 & $27,2 \%$ \\
\hline & $\mathrm{L}^{*}+\mathrm{H} \mathrm{H} \%$ & 3 & $27,2 \%$ \\
\hline & $\mathrm{L}^{*}+\mathrm{H}$ & 1 & $9,1 \%$ \\
\hline & $\mathrm{L}^{*}+\mathrm{H} \mathrm{L} \%$ & 1 & $9,1 \%$ \\
\hline $\mathrm{T}$ deslocado à direita & $(\mathrm{H}+) \mathrm{L}^{*} \mathrm{~L} \%{ }^{14}$ & 5 & $100 \%$ \\
\hline
\end{tabular}

Assim, observa-se que, nos casos com o tópico in situ inicial, predomina a ocorrência do acento tonal $\mathrm{L}^{*}+\mathrm{H}$ associado ao elemento topicalizado, podendo ocorrer a inserção de pausa e tom de fronteira H\% após esse acento tonal, como representado pela Figura 1.

\footnotetext{
${ }_{12}$ Neste caso, notou-se a ocorrência de tom adicional $\mathrm{L}+\mathrm{H}$ associado à primeira sílaba da $\omega$ topicalizada composta por 2 sílabas pretônicas (ex.: "angolanas"). Sobre tons adicionais do PB, conferir, entre outros, Frota e Vigário (2000), Tenani (2002), Fernandes (2007), Fernandes-Svartman (2009) e Toneli (2014). Segundo Tenani (2002), Fernandes (2007) e Fernandes-Svartman (2009), esse tipo de tom está relacionado à sílaba portadora de acento secundário em $\mathrm{PB}$.

${ }^{13}$ Nos casos das expressões em que são encontradas as configurações tonais $\mathrm{H}^{*}+\mathrm{L} \mathrm{L} \%$, $\mathrm{H}^{*}+\mathrm{L}$ e $\mathrm{L}^{*}+\mathrm{H} \mathrm{H} \%$, pode haver tom adicional $(\mathrm{H}$ ou $\mathrm{L}+\mathrm{H})$ associado à primeira sílaba da $\omega$ topicalizada composta por 2 sílabas pretônicas (ex.: "jornalistas").

${ }_{14}$ Os parênteses indicam que pode ou não ocorrer o tom alto, tendo sido observada uma ocorrência da configuração $\mathrm{H}+\mathrm{L}^{*} \mathrm{~L} \%$.
} 
Figura 1 - Segmentação e análise entoacional da sentença "As angolanas, ofereceram especiarias aos jornalistas" produzida por CS. (Tópico in situ inicial) ${ }^{15}$

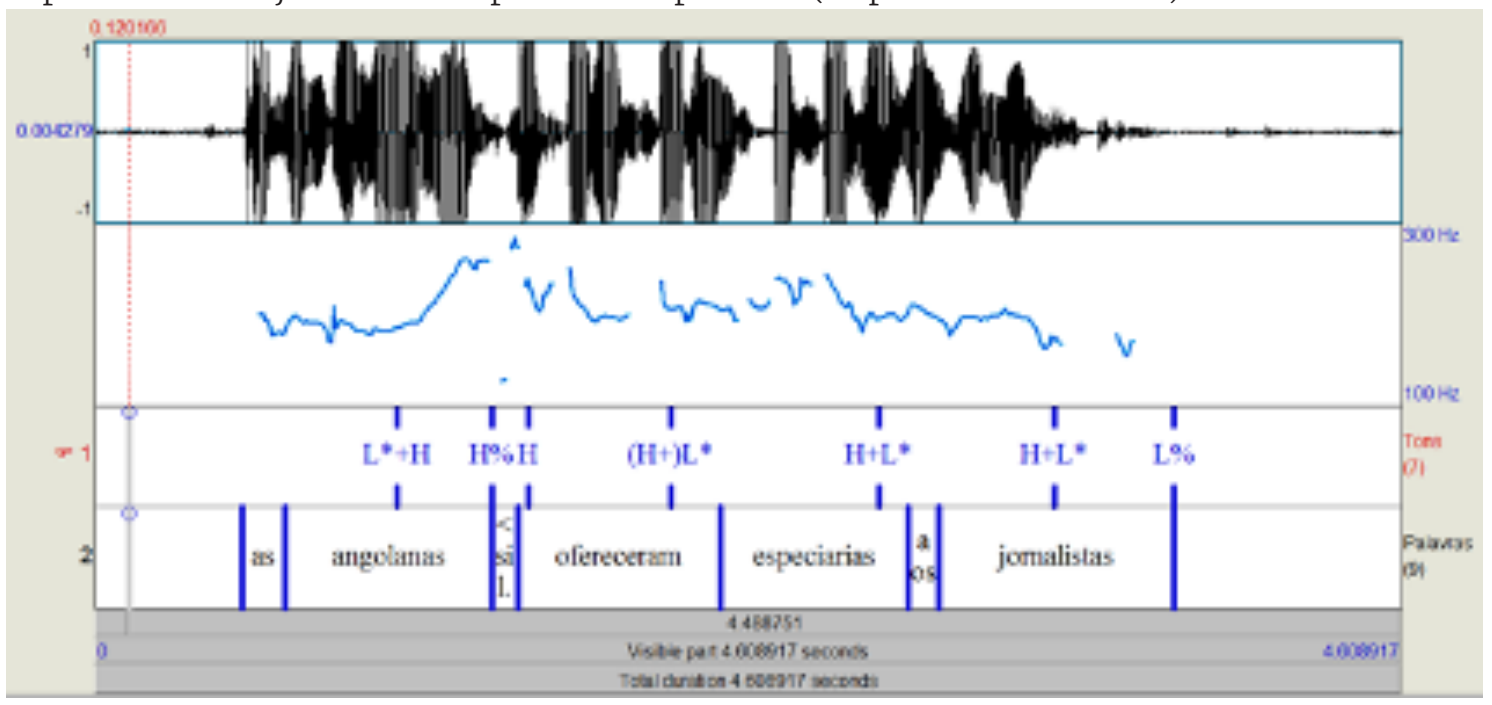

Fonte: Elaboração própria.

Já com o tópico in situ em posição final, em todas as ocorrências, observou-se o acento tonal descendente $\mathrm{H}+\mathrm{L}^{*}$, seguido por tom de fronteira baixo $\mathrm{L} \%$, característico de final de sentença declarativa em português (FROTA, 2000; FROTA; VIGÁRIO, 2000; TENANI, 2002; FERNANDES, 2007; FROTA et al., 2015a; entre outros). Além disso, à exceção de um caso, é recorrente também a inserção de pausa antes da expressão topicalizada em posição final e tom de fronteira baixo L\%, conforme ilustrado pela Figura 2.

Figura 2 - Segmentação e análise entoacional da sentença "As angolanas ofereceram especiarias, aos jornalistas" produzida por EF. (Tópico in situ final)

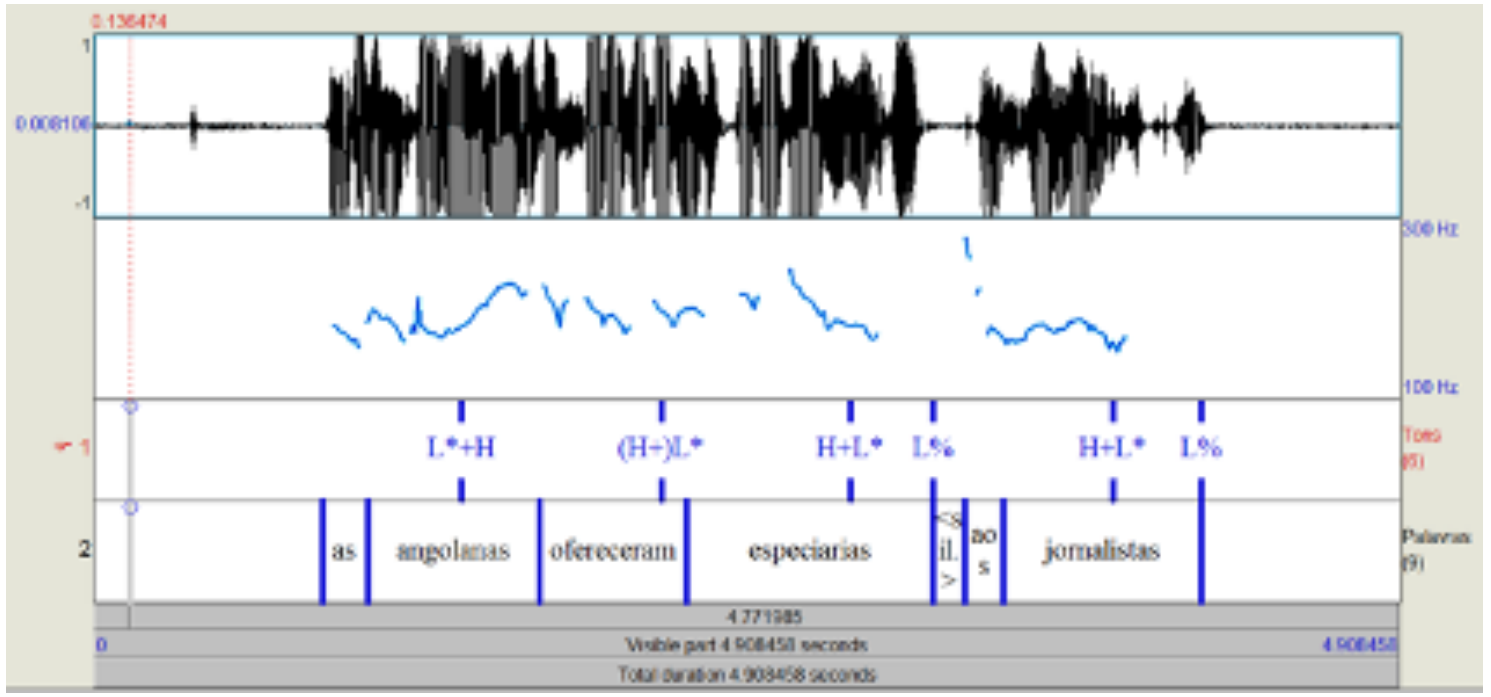

Fonte: Elaboração própria.

${ }_{15} \mathrm{O}$ trecho em negrito indica a expressão topicalizada ou focalizada na sentença. 
V. 10 (1)

256-282

jan-abr

2020

Nos casos com o tópico deslocado à esquerda, há a predominância de associação do acento tonal $\mathrm{H}^{*}+\mathrm{L}$ à expressão topicalizada, com a possibilidade de haver, após esse acento tonal, a inserção de pausa e um tom de fronteira baixo L\% - ver Figura 3.

Figura 3 - Segmentação e análise entoacional da sentença "As rosas, as alunas ofereceram ao monitor" produzida por CS. (Tópico deslocado à esquerda)

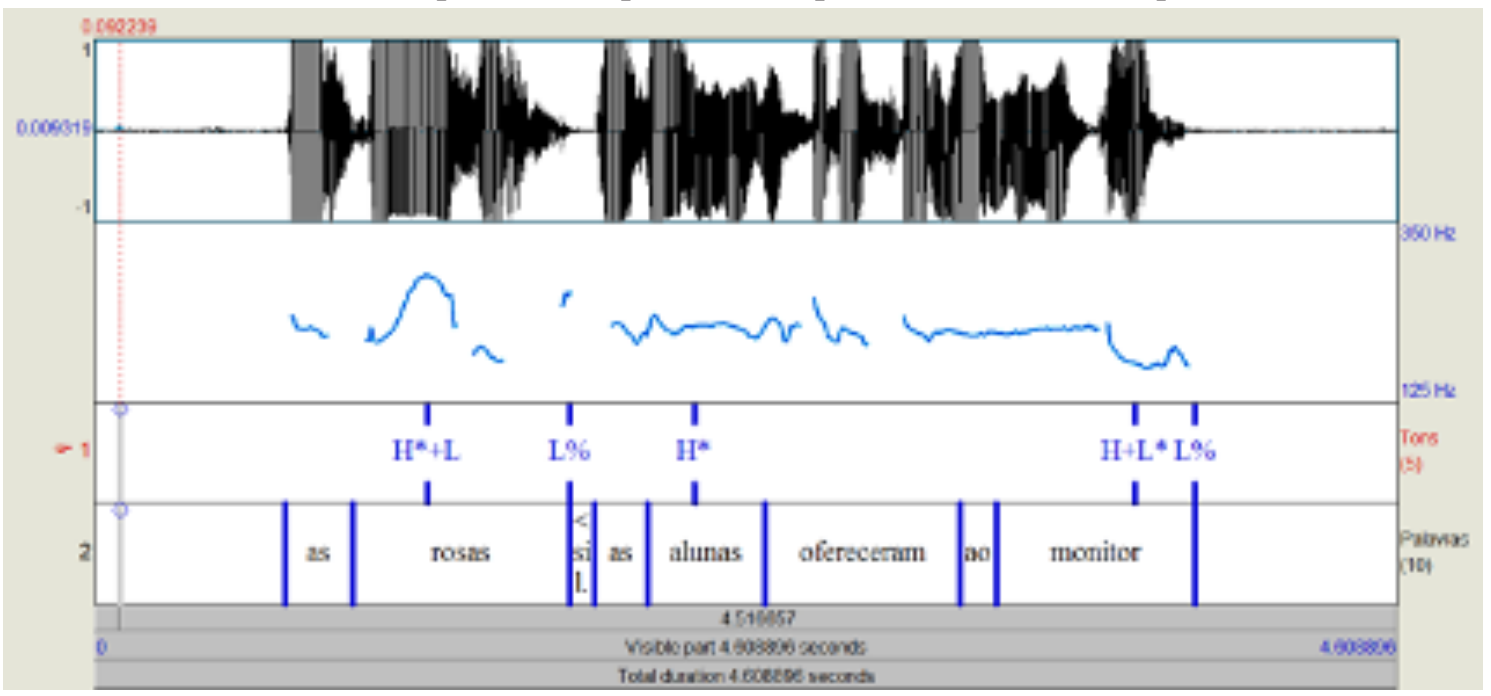

Fonte: Elaboração própria.

Já com o tópico deslocado à direita, observa-se um contorno similar ao de enunciados com tópico in situ final, sendo predominante a associação do acento tonal $\mathrm{H}+\mathrm{L}^{*}$ ao elemento topicalizado, seguido por um tom de fronteira baixo L\%, característico de final de sentença declarativa em português, e pausa antecedendo o referido elemento, como mostra a figura 4. Além disso, com menor frequência, podem ocorrer também as configurações tonais $\mathrm{L} * \mathrm{~L} \%$ e ! H+L* $\mathrm{L} \%$ associadas ao elemento topicalizado, pausa e tom de fronteira baixo L\% antes da expressão topicalizada. 
Figura 4 - Segmentação e análise entoacional da sentença "Ofereceram especiarias aos jornalistas, as angolanas" produzida por EF. (Tópico deslocado à direita)

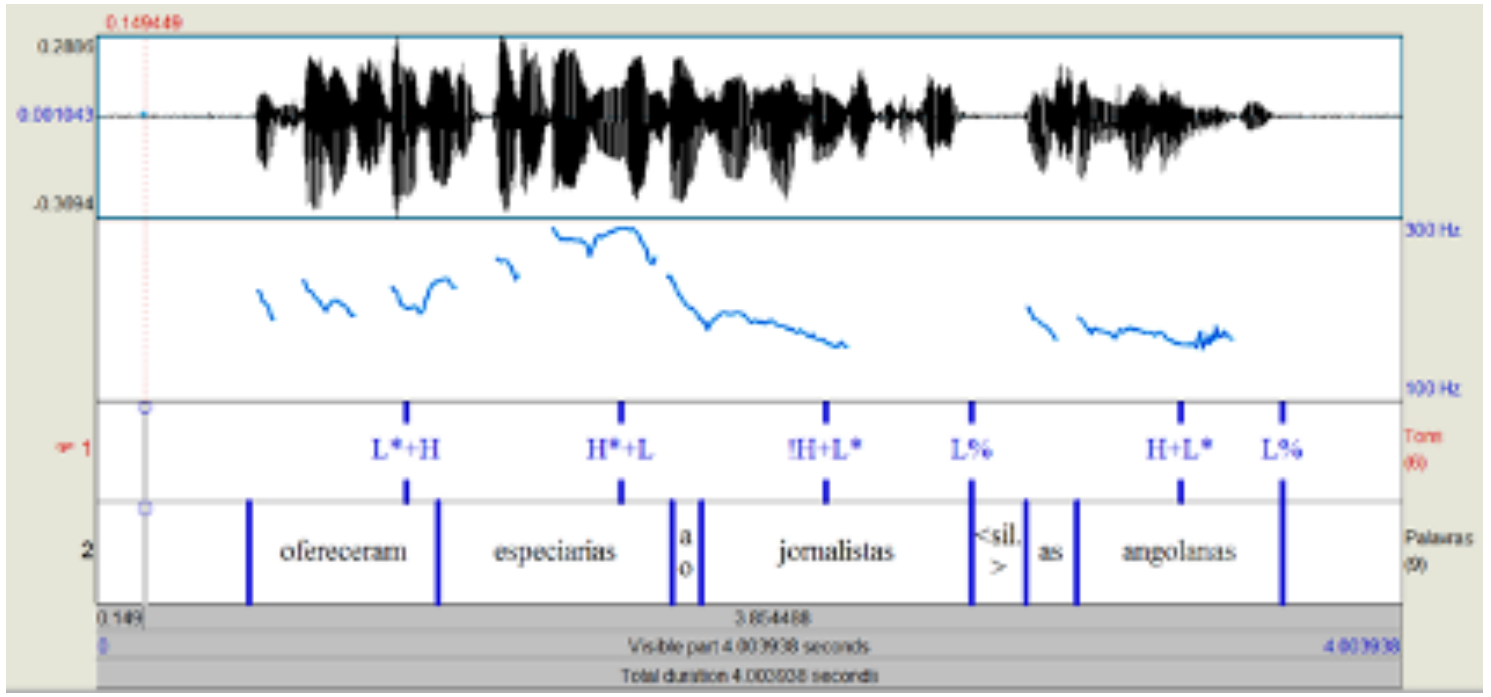

Fonte: Elaboração própria.

Foco

Por sua vez, no que diz respeito às construções com foco, o quadro 2 mostra os tipos de configurações tonais encontradas associadas aos elementos focalizados, bem como os valores absolutos e percentuais de ocorrência, de acordo com a posição do elemento focalizado na sentença. Cabe acrescentar que foco contrastivo e foco informacional não foram diferenciados na quantificação, pois, em nossos dados, apresentaram o mesmo tipo de prosodização. 
V. 10 (1)

256-282

jan-abr 2020

Quadro 2 - Ocorrências das configurações tonais associadas aos elementos focalizados em diferentes posições na sentença

\begin{tabular}{|c|c|c|c|}
\hline Posição do foco (F) & Configuração tonal & $\begin{array}{l}\text { Número de } \\
\text { ocorrências }\end{array}$ & \% de ocorrência \\
\hline \multirow{10}{*}{ F inicial ${ }^{16}$} & $\mathrm{~L} *+\mathrm{H}$ & 7 & $30,4 \%$ \\
\hline & $\mathrm{L} *+\mathrm{H} \mathrm{H} \%$ & 4 & $17,3 \%$ \\
\hline & $\mathrm{H}^{*}+\mathrm{L}$ & 4 & $17,3 \%$ \\
\hline & $\mathrm{H}+\mathrm{L}^{*} \mathrm{~L}-$ & 2 & $8,6 \%$ \\
\hline & $\mathrm{H}+\mathrm{L}^{*}$ & 1 & $4,3 \%$ \\
\hline & $\mathrm{H}+\mathrm{L} * \mathrm{H} \%$ & 1 & $4,3 \%$ \\
\hline & $\mathrm{H}+\mathrm{L} * \mathrm{~L} \%$ & 1 & $4,3 \%$ \\
\hline & $\mathrm{H}+\mathrm{L} *$ !HL- & 1 & $4,3 \%$ \\
\hline & $\mathrm{L}+\mathrm{H}^{*}$ & 1 & $4,3 \%$ \\
\hline & $\mathrm{L}+\mathrm{H}^{*} \mathrm{~L}-$ & 1 & $4,3 \%$ \\
\hline $\begin{array}{l}\text { F final com } \varphi \text { não- } \\
\text { ramificado }\end{array}$ & $\mathrm{H}+\mathrm{L}^{*} \mathrm{~L} \%{ }^{17}$ & 12 & $100 \%$ \\
\hline \multirow{6}{*}{$\begin{array}{l}\text { F na primeira } \omega \text { de } \varphi \\
\text { ramificado final }\end{array}$} & $\mathrm{H}+\mathrm{L}^{*}$ & 4 & $33,3 \%$ \\
\hline & $\mathrm{L}+\mathrm{H}^{*}$ & 4 & $33,3 \%$ \\
\hline & $\mathrm{H}+\mathrm{L} * \mathrm{H} \%$ & 1 & $8,3 \%$ \\
\hline & $\mathrm{L}+j \mathrm{H}^{*} \mathrm{~L} \%$ & 1 & $8,3 \%$ \\
\hline & $\mathrm{L}^{*}+\mathrm{H}$ & 1 & $8,3 \%$ \\
\hline & $\mathrm{L}^{*}$ & 1 & $8,3 \%$ \\
\hline
\end{tabular}

Fonte: Elaboração própria.

Nas construções com foco em posição inicial, encontra-se, na maioria dos casos, o contorno ascendente, representado pelo acento tonal $\mathrm{L}^{*}+\mathrm{H}$, associado ao elemento focalizado, podendo haver pausa e um tom de fronteira H\% após o acento tonal, conforme ilustrado pela Figura 5. Alternativamente, ainda que em menor frequência, pode haver um acento frasal L- ou !HL- associado à fronteira direita do $\varphi$ que contém a expressão focalizada e, nesse caso, não há pausa após essa expressão.

\footnotetext{
${ }^{16}$ Nos casos das expressões em que são encontradas as configurações tonais $\mathrm{L}^{*}+\mathrm{H}$, $\mathrm{H}^{*}+\mathrm{L}, \mathrm{H}+\mathrm{L}^{*} \mathrm{~L}-, \mathrm{H}+\mathrm{L}^{*} \mathrm{~L} \%$ e $\mathrm{H}+\mathrm{L}^{*}$ ! HL\%, pode ocorrer tom adicional $(\mathrm{L}+\mathrm{H}$ ou $\mathrm{H})$ associado à primeira sílaba da $\omega$ focalizada formada por 1 (ex.: "galã") ou 2 sílabas pretônicas (ex.: "angolanas").

${ }^{17}$ Neste caso, pode ocorrer tom adicional L+H ou H associado à primeira sílaba da $\omega$ focalizada composta por 2 sílabas pretônicas (ex.: "jornalistas").
} 
Figura 5 - Segmentação e análise entoacional da sentença "O galã andava de Porsche" produzida por EF. (Foco em posição inicial)

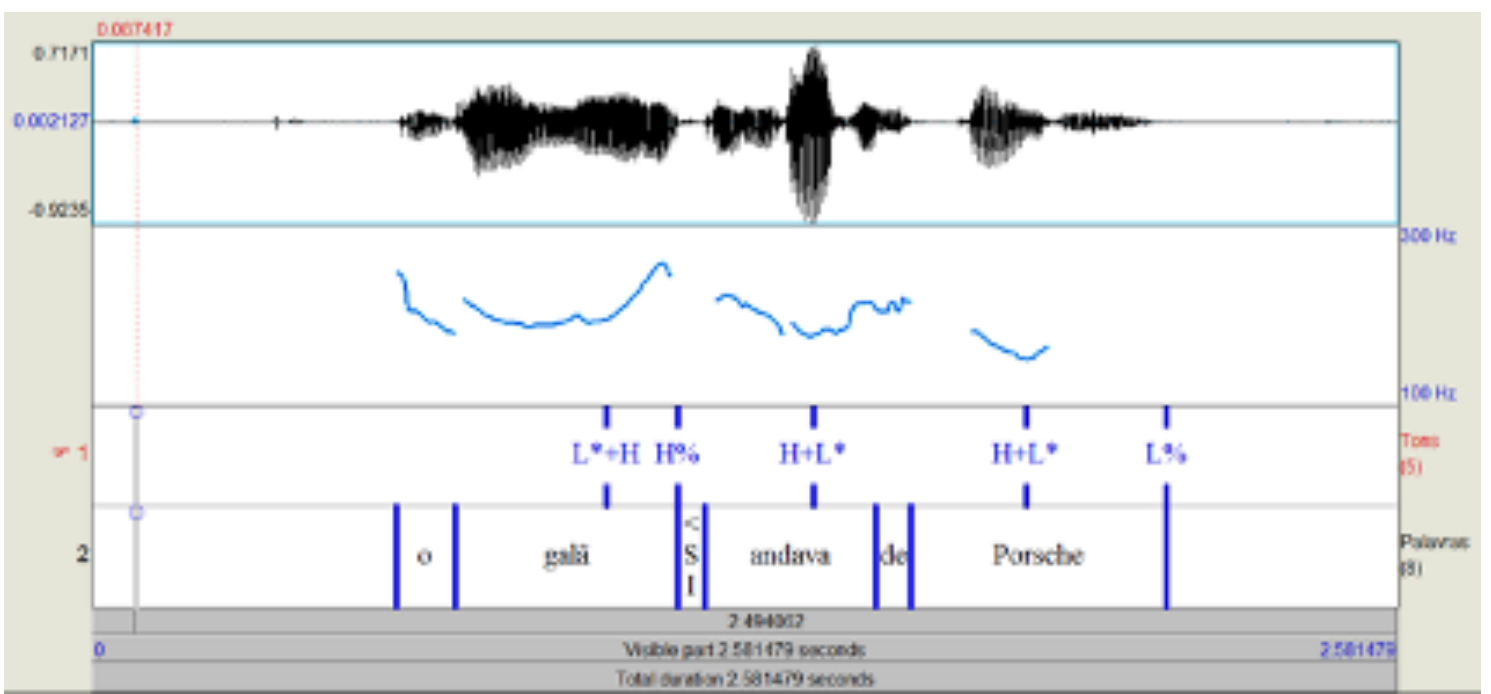

Fonte: Elaboração própria.

Em comparação, tal tipo de contorno, representado pelo acento tonal ascendente $\mathrm{L}^{*}+\mathrm{H}$, é similar ao observado para o elemento inicial em construções declarativas neutras nos dados, como ilustrado pela Figura 6. Porém, no caso das sentenças neutras, não são encontrados pausa após o elemento inicial e tom relacionado à fronteira (tom de fronteira ou acento frasal).

Figura 6 - Segmentação e análise entoacional da sentença "O galã andava de Porsche" produzida por EF. (Sentença declarativa neutra)

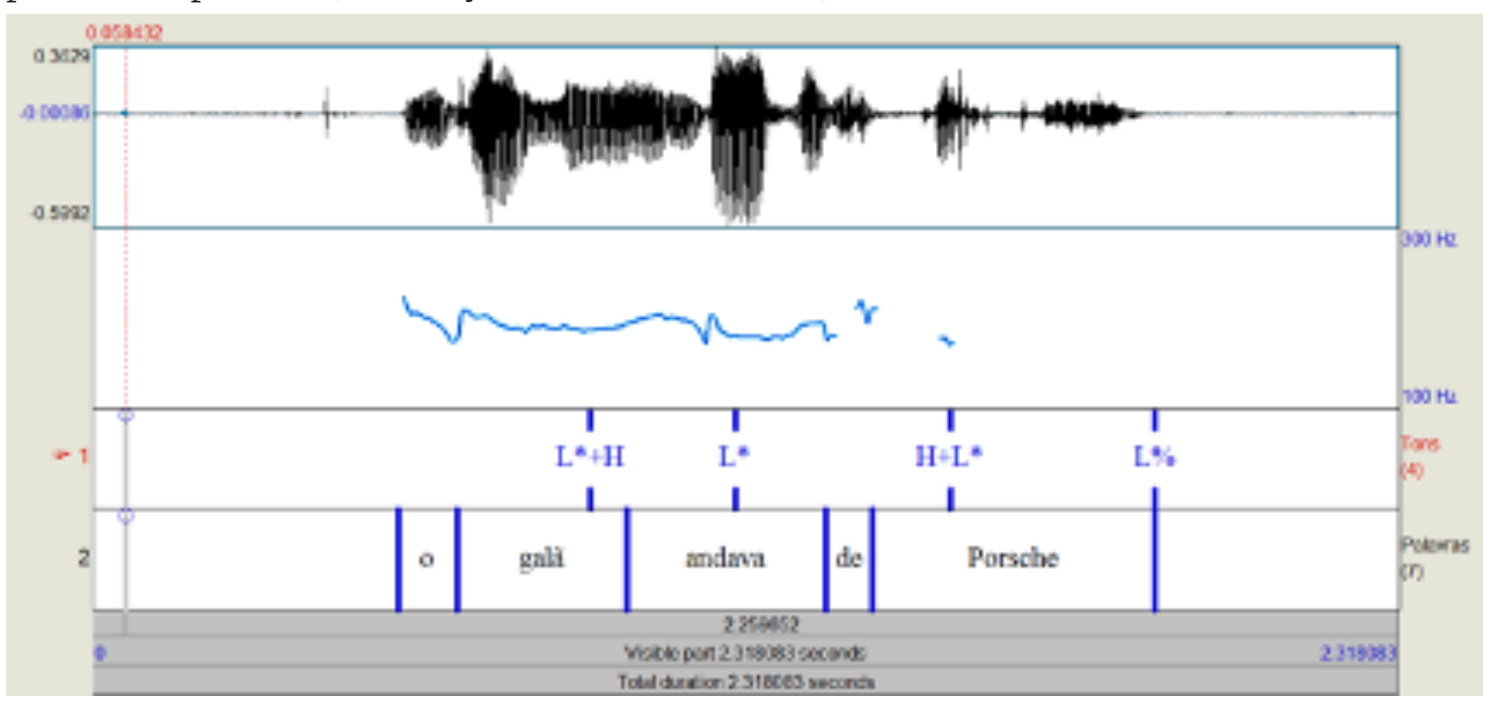

Fonte: Elaboração própria.

Quando o foco está em um constituinte não-ramificado (formado por uma única $\omega$ ) em posição final, em todos os casos, notou-se o acento tonal $\mathrm{H}+\mathrm{L}^{*}$ associado a esse elemento, seguido por um tom de fronteira 
V. 10 (1)

256-282

jan-abr

2020

baixo L\%, característico de final de sentença declarativa em PB (FROTA; VIGÁRIO, 2000; TENANI, 2002; FERNANDES, 2007; FROTA et al., 2015; entre outros), como representado pela Figura 7. Além disso, como também mostra a Figura 7, em alguns casos, pode haver, antecedendo a expressão focalizada, pausa e um tom de fronteira $\mathrm{L} \%$ ou $\mathrm{H} \%$ associado à fronteira direita do I antecedente, que não contém a expressão focalizada. Com isso, a expressão focalizada em posição final forma um I independente, resultando no fraseamento da sentença em dois Is distintos: um que contém a expressão focalizada e outro que contém o restante da sentença. Nota-se ainda que a configuração tonal $\mathrm{H}+\mathrm{L} * \mathrm{~L} \%$ associada ao elemento focalizado em posição final é semelhante à configuração tonal do contorno final de sentenças declarativas neutras, com a diferença de que, neste caso, não há pausa antes do elemento final, como pode ser observado no exemplo de sentença neutra representado pela Figura 6.

Figura 7 - Segmentação e análise entoacional da sentença "As angolanas ofereceram especiarias aos jornalistas" produzida por LC. (Foco em posição final em constituinte não-ramificado)

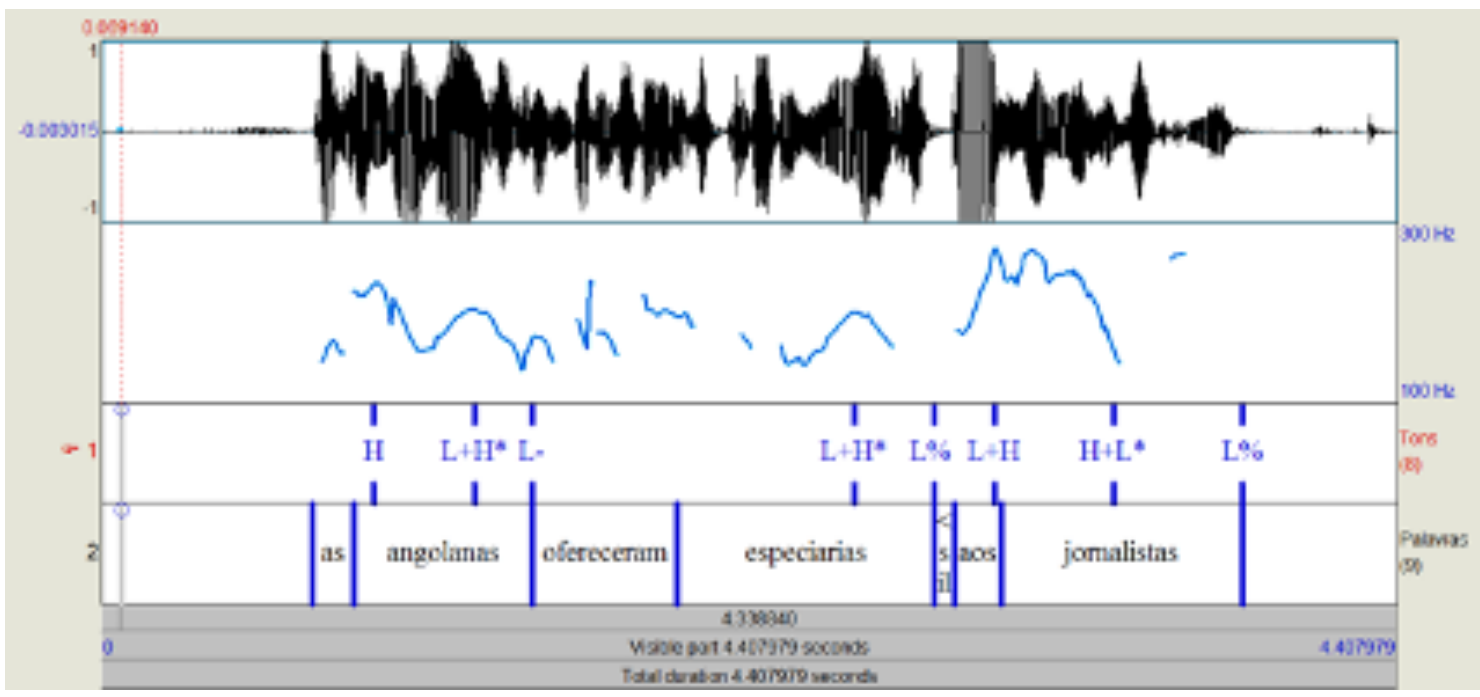

Fonte: Elaboração própria.

Quando o constituinte final focalizado é ramificado e o foco está na primeira $\omega$ de tal constituinte, nota-se, com maior frequência, os contornos $\mathrm{H}+\mathrm{L}^{*}$ e $\mathrm{L}+\mathrm{H}^{*}$ associados à $\omega$ focalizada e à segunda $\omega$ do constituinte ramificado, respectivamente, podendo ocorrer pausa e um tom de fronteira $\mathrm{H} \%$ ou $\mathrm{L} \%$ na fronteira direita do I que contém a $\omega$ focalizada e um tom de fronteira L\% na fronteira direita do I que contém a segunda $\omega$ do constituinte ramificado final, como aparece ilustrado na Figura 8. Isso indica que, sendo o foco marcado na primeira $\omega$ do constituinte ramificado, tal constituinte pode ser fraseado em Is distintos. 
Figura 8 - Segmentação e análise entoacional da sentença "O cantor cantou uma manhã angelical" produzida por CS. (Foco na primeira $\omega$ de constituinte ramificado final)

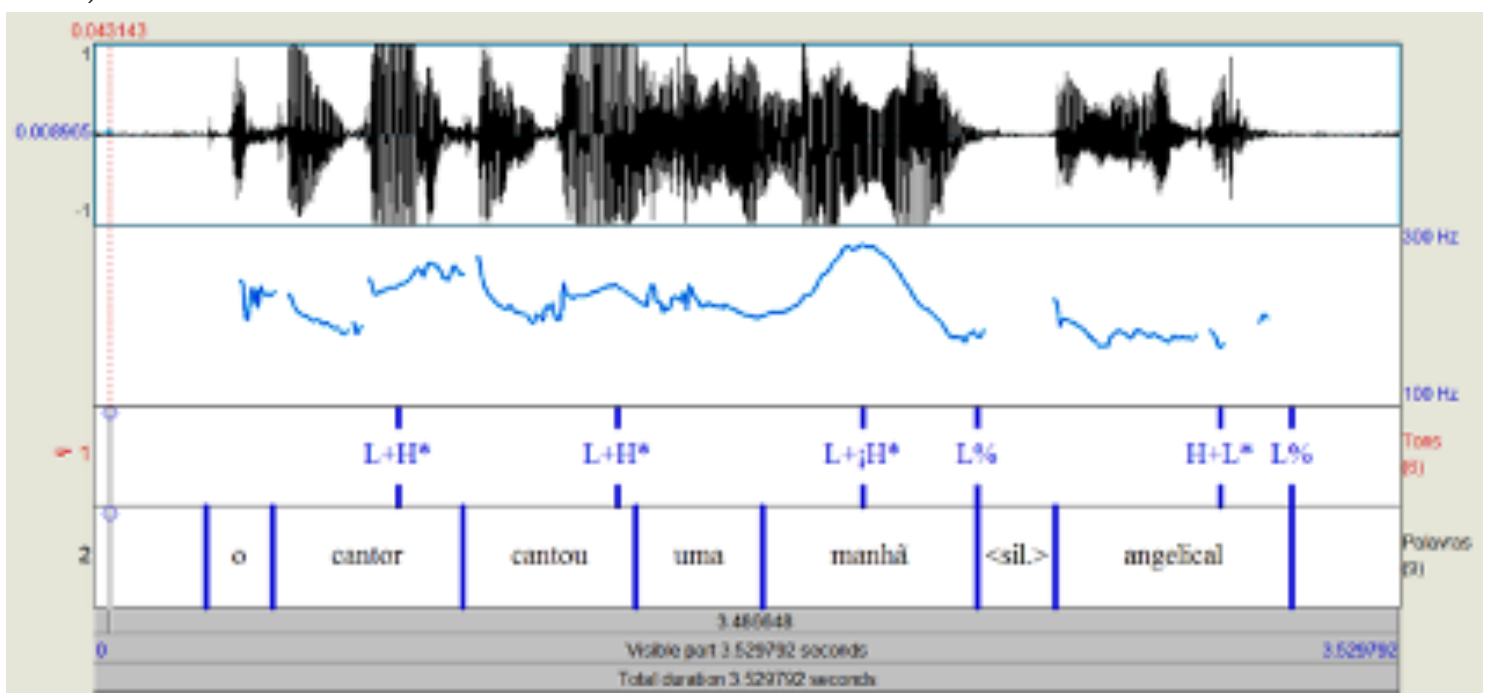

Fonte: Elaboração própria.

Em comparação, assim como nos casos descritos acima, com foco final em constituintes não-ramificado e ramificado, ocorre o mesmo tipo de acento tonal nuclear, $\mathrm{H}+\mathrm{L}^{*}$, presente em sentenças declarativas neutras, como representado pelas Figuras 9 e 10.

Figura 9 - Segmentação e análise entoacional da sentença "As angolanas ofereceram especiarias aos jornalistas" produzida por EF. (Sentença declarativa neutra)

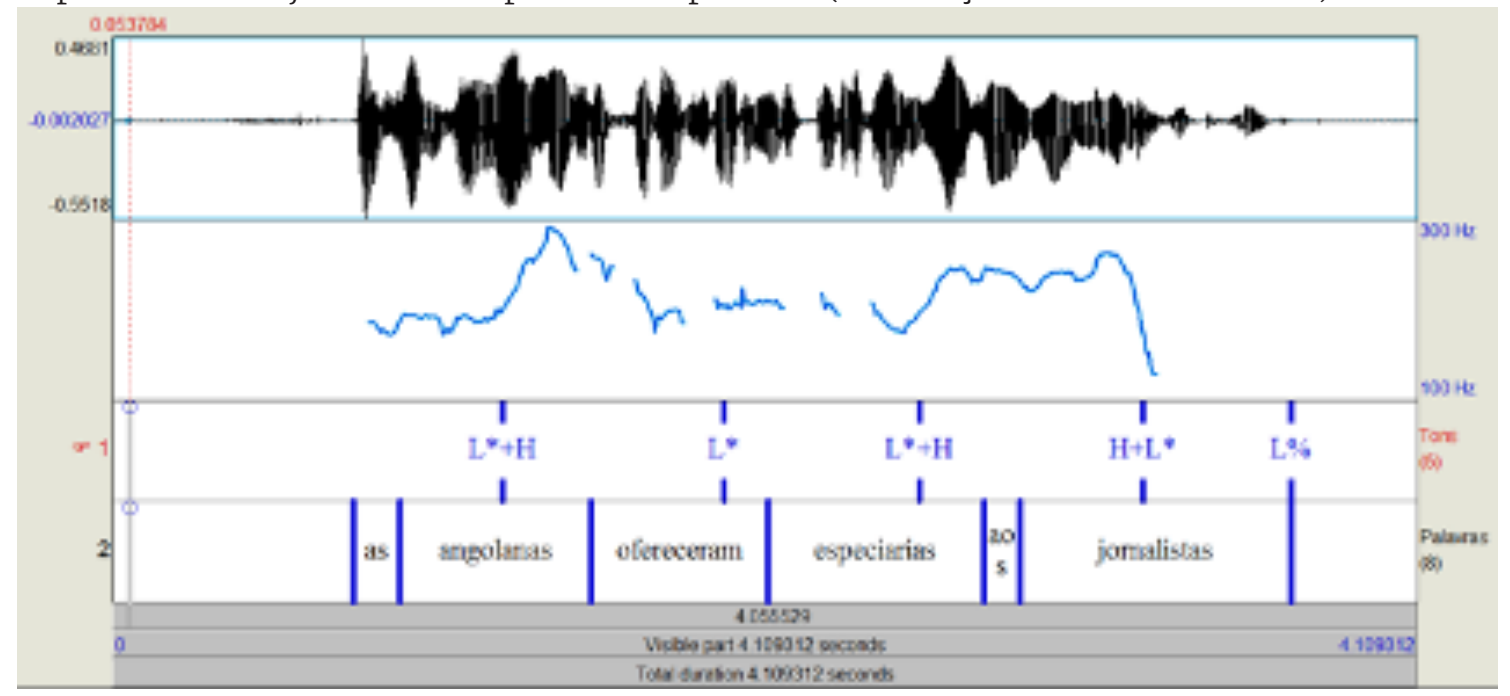

Fonte: Elaboração própria. 
V. 10 (1) 256-282 jan-abr 2020

Figura 10 - Segmentação e análise entoacional da sentença "O cantor cantou uma manhã angelical" produzida por CS. (Sentença declarativa neutra)

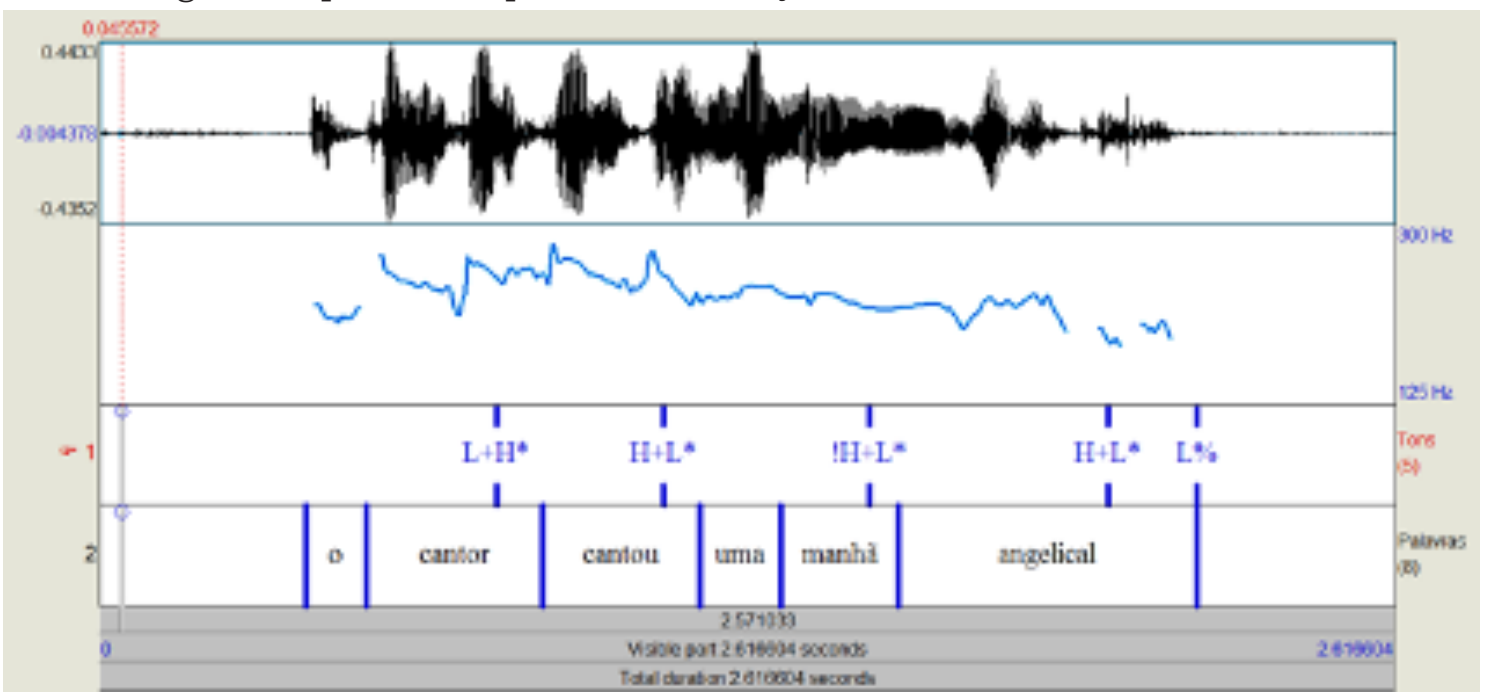

Fonte: Elaboração própria.

\section{Discussão}

Os resultados preliminares deste estudo apontam para similaridades e diferenças em relação aos resultados de estudos anteriores para outras variedades do português. Nos quadros 3 e 4, abaixo, é apresentada uma comparação dos tipos de configuração tonal associada à marcação de tópico e foco entre o dialeto falado na cidade de São Paulo e as demais variedades do português já descritas.

Quadro 3 - Comparação dos contornos nucleares de expressões topicalizadas em sentenças declarativas em variedades do português brasileiro e do português europeu, de acordo com a sua posição na sentença.

\begin{tabular}{|c|c|c|c|c|}
\hline $\begin{array}{c}\text { Variedade do } \\
\text { português }\end{array}$ & T in situ inicial & T in situ final & $\begin{array}{c}\text { T deslocado à } \\
\text { esquerda }\end{array}$ & $\begin{array}{c}\text { T deslocado à } \\
\text { direita }\end{array}$ \\
\hline $\begin{array}{c}\text { PB São Paulo } \\
\text { (SP) }\end{array}$ & $\begin{array}{c}\mathrm{L}^{*}+\mathrm{H} \\
\mathrm{L}^{*}+\mathrm{H} \mathrm{H} \%\end{array}$ & $\mathrm{H}+\mathrm{L}^{*} \mathrm{~L} \%$ & $\mathrm{H}^{*}+\mathrm{L} \mathrm{L} \%$ & $(\mathrm{H}+) \mathrm{L}^{*} \mathrm{~L} \%$ \\
\hline $\mathrm{PB}(\mathrm{RJ})$ & $\begin{array}{c}\mathrm{H}^{*}+\mathrm{L} \mathrm{H}^{*} \mathrm{H} \% \\
\mathrm{H}^{*} \mathrm{~L}+\mathrm{H}^{*} \mathrm{H} \%\end{array}$ & & $\begin{array}{c}\mathrm{H}^{*}+\mathrm{L} \mathrm{H} \mathrm{H}^{*} \mathrm{H} \% \\
\mathrm{H}^{*} \mathrm{~L}+\mathrm{H} * \mathrm{~L} \%\end{array}$ & \\
\hline PE standard & $\begin{array}{c}\mathrm{L}^{*}+\mathrm{H} \mathrm{H} \% \\
\mathrm{H}+\mathrm{L}^{*} \mathrm{~L} \%\end{array}$ & $\mathrm{H}+\mathrm{L}^{*} \mathrm{H} \% / \mathrm{L} \%$ & & \\
\hline PE Porto & $(\mathrm{H}+) \mathrm{L}^{*} \mathrm{H} \%$ & $\mathrm{H} \%(\mathrm{H}+) \mathrm{L}^{*} \mathrm{~L} \%$ & $\mathrm{~L}^{*}(+\mathrm{H}) \mathrm{H} \%$ & $\mathrm{~L} \%(\mathrm{H}+) \mathrm{L}^{*} \mathrm{~L} \%$ \\
\hline PE Évora & $(\mathrm{H}+) \mathrm{L}^{*} \mathrm{H} \% / \mathrm{L} \%$ & $(\mathrm{H}+) \mathrm{L}^{*} \mathrm{H} \% / \mathrm{L} \%$ & $(\mathrm{H}+) \mathrm{L}^{*} \mathrm{H} \% / \mathrm{L} \%$ & $(\mathrm{H}+) \mathrm{L}^{*} \mathrm{~L} \%$ \\
\hline
\end{tabular}

Fonte: Elaboração própria. 
Quadro 4 - Comparação dos contornos nucleares de expressões focalizadas em sentenças declarativas em variedades do português brasileiro e do português europeu, de acordo com a sua posição na sentença

\begin{tabular}{|c|c|c|}
\hline Variedade do português & F inicial & F final \\
\hline PB São Paulo (SP) & $\mathrm{L}^{*}+\mathrm{H}(\mathrm{H} \%)$ & $\begin{array}{c}\mathrm{H}+\mathrm{L}^{*}(\mathrm{~L} \%) \\
\mathrm{L}+\mathrm{H}^{*}\end{array}$ \\
\hline PB Campinas (SP) & $\begin{array}{c}\mathrm{L}^{*}+\mathrm{H}(\mathrm{L}-) \\
\mathrm{H}^{*}+\mathrm{L}(\mathrm{L} \%) \\
\mathrm{L}^{*} \mathrm{H}- \\
\end{array}$ & $\mathrm{H}+\mathrm{L} * \mathrm{~L} \%$ \\
\hline PB (BA e $M G)$ & $\mathrm{L}^{*}+\mathrm{H}$ & $\begin{array}{l}\mathrm{H}+\mathrm{L} * \mathrm{~L} \% \\
\mathrm{~L} *+\mathrm{H} \%\end{array}$ \\
\hline $\mathrm{PB}(\mathrm{RS})$ & $\mathrm{L}+\mathrm{H}^{*}$ & $\begin{array}{c}\mathrm{H}+\mathrm{L}^{*} \mathrm{~L} \% \\
\mathrm{~L}+\mathrm{H}^{*} ! \mathrm{H} \%\end{array}$ \\
\hline PE standard & $\begin{array}{c}\mathrm{H}^{*}+\mathrm{L} \\
\mathrm{H}+\mathrm{L}^{*} \mathrm{~L} \% \\
\mathrm{~L} \% \\
\end{array}$ & $\mathrm{H}+\mathrm{L} * \mathrm{~L} \%$ \\
\hline PE Porto & $\mathrm{H}^{*}+\mathrm{L} \mathrm{L} \%$ & $\begin{array}{c}H^{*}+\mathrm{L} \mathrm{L} \% \\
H+\mathrm{L}^{*} \mathrm{~L} \% \\
\mathrm{~L}^{*} \mathrm{~L} \%\end{array}$ \\
\hline PE Alentejo & $\mathrm{H}^{*}+\mathrm{L} \mathrm{L} \%$ & $\mathrm{~L}^{*} \mathrm{~L} \%$ \\
\hline PE Algarve & $\mathrm{H}^{*}+\mathrm{L} \mathrm{L} \%$ & $\mathrm{H}+\mathrm{L} * \mathrm{~L} \%$ \\
\hline
\end{tabular}

Fonte: Elaboração própria.

Quanto às construções com tópico, na variedade paulistana do $\mathrm{PB}$, tópicos-sujeito em posição inicial parecem se distinguir dos tópicos deslocados à esquerda pelo tipo de acento tonal e pelo tipo de tom de fronteira, sendo o primeiro mais frequentemente marcado por um acento tonal ascendente $\mathrm{L}^{*}+\mathrm{H}$, e o segundo, por um acento tonal descendente $\mathrm{H}^{*}+\mathrm{L}$. Tais resultados divergem do que Moraes e Orsini (2003, 2005) observaram para a variedade carioca do PB. Conforme os autores, tanto tópicos-sujeito como os deslocados à esquerda são marcados pelo mesmo tipo de acento tonal, sendo a distinção feita apenas pelo tipo de tom de fronteira que segue o acento tonal: $\mathrm{H} \%$ para tópicos-sujeito e L\% para tópicos deslocados à esquerda. Em posição final, porém, nos dados com tópicos in situ e deslocados à direita, encontrou-se o mesmo tipo de acento tonal: $\mathrm{H}+\mathrm{L}^{*}$. Além disso, os tópicos deslocados à esquerda parecem se distinguir dos deslocados à direita pelo tipo de acento tonal associado à sílaba tônica do elemento topicalizado. Isto é, no primeiro caso, encontrou-se o acento tonal $\mathrm{H}^{*}+\mathrm{L}$ (o tom alto está alinhado com a sílaba tônica, e o tom baixo está alinhado com a sílaba postônica) e, no segundo caso, $\mathrm{H}+\mathrm{L}^{*}$ (o tom alto está alinhado com a sílaba pretônica, e o tom baixo está alinhado com a sílaba tônica). Quanto à inserção de pausa, tal estratégia é recorrente em todos os casos com tópico, 
V. 10 (1)

256-282

jan-abr

2020

tanto antecedendo o elemento topicalizado - para tópicos in situ finais e deslocados à direita -, como seguindo o elemento topicalizado - para tópicos in situ iniciais e deslocados à esquerda. A inserção de pausas e a associação de tons de fronteira sugerem que o fraseamento prosódico em Is das sentenças que contêm a expressão topicalizada é afetado por esse tipo de expressão, sendo elas fraseadas em dois Is independentes: um contendo a expressão topicalizada e o outro, o restante da sentença.

Já nas construções com foco, de maneira similar aos resultados encontrados por Fernandes (2007), para sujeitos focalizados em posição inicial, encontrou-se, com mais frequência, a marcação do acento tonal $\mathrm{L}^{*}+\mathrm{H}$, podendo haver um tom de fronteira $\mathrm{H} \%$ seguindo esse acento tonal e pausa. Ademais, cabe notar que, embora trate também de uma variedade paulista do PB, Fernandes notou apenas a possibilidade de ocorrência, após o acento $\mathrm{L}^{*}+\mathrm{H}$, de um acento frasal associado à fronteira direita do $\varphi$ que contém a expressão focalizada, e não a associação de um tom de fronteira e a inserção de pausa. Tal divergência em relação aos resultados aqui obtidos é uma questão que merece ser investigada em estudos futuros. Por sua vez, para elementos focalizados em posição final, predomina a associação do acento tonal $\mathrm{H}+\mathrm{L}^{*}$, podendo esse acento tonal ser seguido de um tom de fronteira L\% e pausa, se o elemento focalizado não é a primeira $\omega$ de constituinte ramificado.

Além disso, os dados quantitativos sugerem que, enquanto tópicos in situ iniciais e finais e tópicos deslocados à esquerda ou à direita podem formar Is independentes, sendo frequente a inserção de pausa em todos os casos, expressões focalizadas não tendem a formar Is independentes. Isso porque a inserção de pausa é menos recorrente antecedendo foco em posição final ou seguindo foco em posição inicial.

Em comparação às sentenças com tópico do $\mathrm{PE}$, a variedade paulistana do PB parece se assemelhar quanto à configuração tonal da expressão topicalizada, às variedades standard (de Lisboa), do Porto, de Braga, de Castelo Branco e de Évora do PE. Nessas variedades, tópicos in situ iniciais tendem a ser marcados também pelo contorno $\mathrm{L}^{*}+\mathrm{H} \mathrm{H} \%$ (FROTA 2000, 2014 para a variedade lisboeta; BARROS, 2014 para as variedades do Porto, de Braga, de Castelo Branco e de Évora), embora Frota (2000, 2014) tenha encontrado também a configuração tonal $\mathrm{H}+\mathrm{L} * \mathrm{~L} \%$ associada a tópicos in situ iniciais na variedade lisboeta. Em sentenças com tópico in situ final, em todas as variedades do $\mathrm{PE}$, também predomina o contorno $\mathrm{H}+\mathrm{L}^{*} \mathrm{~L} \%$ associado à expressão topicalizada, contorno típico de sentenças declarativas do português. Sobre o fraseamento prosódico, todas 
as variedades do PE analisadas por Frota (2000, 2014) e Barros (2014) se assemelham às variedades paulistana e carioca do $\mathrm{PB}$ quanto à tendência de os tópicos formarem Is independentes, sendo que, nas variedades standard e do Porto, tópicos iniciais tendem a ser seguidos de pausa e, nas demais variedades, é frequente a ocorrência apenas de um tom de fronteira alto. Porém, sobre o tipo de marcação de fronteira de I, notou-se que, enquanto - nas variedades do PE - as fronteiras de I podem ser marcadas apenas por tom de fronteira, nas variedades do PB, as fronteiras de I são marcadas tanto por tom de fronteira como por pausa.

Já quanto às sentenças com foco, a variedade paulistana do PB parece divergir das variedades standard do Porto, do Algarve e do Alentejo do PE. Nessas variedades, para elementos focalizados em posição inicial, predomina o contorno $\mathrm{H}^{*}+\mathrm{L}$, podendo ser seguido por tom de fronteira L\%. Em posição final, se o elemento focalizado pertence a um $\varphi$ ramificado, predomina o contorno $\mathrm{L}^{*}+\mathrm{H} \mathrm{H}+\mathrm{L} * \mathrm{~L} \%$ e, se o elemento focalizado pertence a um $\varphi$ final não ramificado, podem ocorrer os contornos $\mathrm{H}+\mathrm{L}^{*} \mathrm{~L} \%$ ou $\mathrm{H}^{*}+\mathrm{L} \mathrm{L} \%$ associados a tal elemento (FROTA, 1997, 2000, 2002; VIGÁRIO, 1998; FERNANDES, 2007; FROTA et al., 2015a). Todavia, para a variedade paulistana do PB, assim como para as variedades mineira e baiana (FROTA et al., 2015a), no caso de foco em posição inicial, é mais frequente a associação do acento tonal ascendente $\mathrm{L}^{*}+\mathrm{H}$, como já referido anteriormente. Pode haver, ainda, seguindo o acento tonal associado ao elemento focalizado em posição inicial, um tom de fronteira $\mathrm{H} \%$ e pausa ou um acento frasal baixo L-, sendo, assim, a expressão focalizada fraseada no mesmo I que contém o restante da sentença. No caso de foco em constituinte final não ramificado, pode ocorrer o acento tonal $\mathrm{H}+\mathrm{L}^{*}$ associado a esse constituinte, seguido de um tom de fronteira L\%, ao contrário das variedades mineira e baiana do $\mathrm{PB}$, em que predomina, nesse caso, o contorno $\mathrm{L}^{*}+\mathrm{H}$, seguido de um tom de fronteira L\% (FROTA et al., 2015a). Se o constituinte for ramificado e com o foco na primeira $\omega$, a associação do acento tonal $\mathrm{L}^{*}+\mathrm{H}$ à $\omega$ focalizada é menos frequente, predominando a associação dos acentos tonais $\mathrm{H}+\mathrm{L}^{*}$ e $\mathrm{L}+\mathrm{H}^{*}$ a essa $\omega$. Ademais, ainda que haja apenas um caso, pode também ocorrer pausa antecedendo o constituinte ramificado final com a primeira $\omega$ focalizada. Diferentemente das demais variedades do PB já descritas, na variedade gaúcha, em posição inicial, predomina o contorno $\mathrm{L}+\mathrm{H}^{*}$ e, em posição final, o contorno $\mathrm{L}+\mathrm{H}^{*}$, seguido por um tom de fronteira alto com downstep, !H\% (FROTA et al., 2015a). 
V. 10 (1)

256-282

jan-abr

2020

\section{Considerações finais}

À semelhança de outras variedades do $\mathrm{PB}$, já descritas em estudos anteriores (MORAES; ORSINI, 2003; ORSINI, 2005; FERNANDES, 2007; TRUCKENBRODT et al., 2009; FROTA et al., 2015; entre outros), os resultados deste estudo indicam que foco e tópico se comportam de modo distinto, principalmente no que se refere ao seu fraseamento prosódico. Isto é, nas construções com tópico, a despeito da sua posição na sentença, expressões topicalizadas tendem a formar um I independente, sendo recorrente a presença de pausa e um tom de fronteira baixo ou alto na sua fronteira direita ou esquerda. Assim, a sentença é fraseada em dois Is distintos: um contendo a expressão topicalizada e outro contendo o restante da sentença. Nas construções com foco, porém, expressões focalizadas, em posição final ou inicial, não parecem necessariamente formar Is independentes, sendo quantitativamente menos recorrente a inserção de pausa, antes ou depois. Assim, a sentença é fraseada em um I, que contém a expressão focalizada e o restante da sentença.

Por fim, este estudo contribui, de maneira original, para os estudos sobre a prosódia do português: a) ao descrever, para a variedade paulistana do $\mathrm{PB}$, as configurações tonais associadas a diversos tipos de expressões topicalizadas e focalizadas; b) ao abordar o fraseamento prosódico das sentenças que contêm essas expressões; c) e ao comparar os resultados obtidos com os já descritos em estudos anteriores sobre o mesmo tema para outras variedades do português. Porém, trabalhos futuros, contemplando mais dados produzidos por mais falantes da variedade paulistana do $\mathrm{PB}$, análises de outras pistas para identificar fronteiras de constituintes prosódicos, como alongamento final, por exemplo, e aplicação de modelagens estatísticas aos dados quantitativos, são ainda necessários para que se confirmem ou infirmem os resultados apresentados neste estudo preliminar.

\section{Referências bibliográficas}

BARROS, N. Fraseamento prosódico em português: uma análise entoacional de enunciados com parentéticas e tópicos em duas variedades do Português Europeu. 2014. 97 f. Dissertação (Mestrado em Linguística) - Faculdade de Letras - Universidade de Lisboa, Lisboa, 2014.

BECKMAN, M.; PIERREHUMBERT, J. Intonational structure in Japanese and English. In: EWEN, C.; ANDERSON, J. (Eds.) Phonology Yearbook III. Cambridge: Cambridge University Press, 1986. 
BOERSMA, P.; WEENINK, D. Praat: doing phonetics by computer [Computer program]. Version 6.0.31. 2017. Disponível em: http://www.praat. org. Acesso em: 06 mar. 2017

CALLOU, D. et al. Topicalização e deslocamento à esquerda: sintaxe e prosódia. In: CASTILHO, A. (Org.). Gramática do português falado: as abordagens. Campinas: UNICAMP / Fapesp, 1993. 3 V.

FERNANDES, F. R. Peso fonológico e foco informacional no sujeito em portugûês europeu. In: ENCONTRO DA ASSOCIAÇÃO PORTUGUESA DE LINGUÍSTICA, 21., 2006, Porto. Actas... - Textos seleccionados. Porto: APL, 2006. p. 371-386.

FERNANDES, F. R. Ordem, focalização e preenchimento em português: sintaxe e prosódia. 2007. 445 f. Tese (Doutorado em Linguística) - Instituto de Estudos da Linguagem - Universidade Estadual de Campinas, Campinas, 2007.

FERNANDES-SVARTMAN, F. R. Acento secundário, atribuição tonal e ênfase em português brasileiro (PB). Estudos Lingüísticos, São Paulo, v. 38, n. 1, p. 47-58, 2009.

FROTA, S. On the prosody and intonation of focus in European Portuguese. In: MARTINEZ-GIL, F.; MORALES-FRONT, A. (Eds.) Issues in the Phonology and Morphology of the Major Iberian Languages. Washington, D.C.: Georgetown University Press, 1997.

FROTA, S. Prosody and focus in European Portuguese: Phonological phrasing and intonation. Nova York: Garland Publishing, 2000.

FROTA, S. Nuclear falls and rises in European Portuguese: a phonological analysis of declarative and question intonation. Probus (Special Issue on Intonation in Romance, edited by José-Ignacio Hualde), Berlim, n. 14(1), p. 113-146, 2002. DOI: 10.1515/prbs.2002.001.

FROTA, S. (Coord.). InAPoP - Interactive Atlas of the Prosody of Portuguese. Projeto de investigação científica (Fundação para a Ciência e a Tecnologia - FCT, PTDC/CLE-LIN/ 119787/2010). Universidade de Lisboa, 2012-2015. Disponível em: http://labfon.letras.ulisboa.pt/InAPoP. Acesso em: 14 set. 2017.

FROTA, S. The intonational phonology of European Portuguese. In: JUN, S. (Ed.) Prosodic Typology II. Oxford: Oxford University Press, 2014.

FROTA, S.; CRUZ, M.; FERNANDES-SVARTMAN, F.; COLLISCHONN, G.; FONSECA, A.; SERRA, C.; OLIVEIRA, P.; VIGÁRIO, M. Intonational variation in Portuguese: European and Brazilian varieties. In: FROTA, S.; PRIETO, P. (Eds.). Intonation in Romance. Oxford: Oxford University Press, 2015a. p. 235-283.

FROTA, S.; OLIVEIRA, P.; CRUZ, M.; VIGÁRIO, M. P-ToBI: Tools for the transcription of Portuguese prosody. Lisboa: Laboratório de Fonética, CLUL/ FLUL, 2015b.

FROTA, S.; VIGÁRIO, M. Aspectos de prosódia comparada: ritmo e entoação no PE e no PB. In: CASTRO, R. V.; BARBOSA, P. (Orgs.) ENCONTRO NACIONAL DA ASSOCIAÇÃO PORTUGUESA DE LINGUÍSTICA, 15., 2000, Coimbra. Actas... Coimbra: APL, 2000. 1 v. p. 533-555. 
V. 10 (1) 256-282 jan-abr 2020

282

LADD, R. Intonational Phonology. Cambridge: Cambridge University Press, 2008.

MORAES, J. A. de; ORSINI, M. T. Análise prosódica das construções de tópico no português do Brasil: estudo preliminar. Letras de Hoje, Porto Alegre, v. 38., n. 4, p. 261-272, 2003.

NESPOR, M.; VOGEL, I. Prosodic Phonology: With a new foreword. Berlim/ Nova York: Mouton de Gruyter, 2007.

ORSINI, M. T. Análise entoacional das construções de tópico. Cadernos do Círculo Fluminense de Estudos Filológicos e Linguísticos, Rio de Janeiro, v. 9, n. 17, 2005. Trabalho apresentado no IX Congresso Nacional de Linguística e Filologia, 2005, Rio de Janeiro. Disponível em: http://www.filologia.org.br/ ixcnlf/17/index. htm. Acesso em: 03 mar. 2017.

PIERREHUMBERT. H. The phonology and phonetics of English intonation. 1980. 401 f. Tese (Doutorado em Linguística) - MIT, Boston, 1980.

SELKIRK, E. Phonology and Syntax: The Relation Between Sound and Structure. Cambridge: MIT Press, 1984.

SELKIRK, E. On derived domains in sentence phonology. In: Phonology Yearbook 3. Cambridge: Cambridge University Press, 1986.

SERRA, C. Realização e percepção de fronteiras prosódicas no português do Brasil: fala espontânea e leitura. 2009. $241 \mathrm{f}$. Tese (Doutorado em Letras) Faculdade de Letras - Universidade Federal do Rio de Janeiro, Rio de Janeiro, 2009.

TENANI, L. Domínios prosódicos no português do Brasil. 2002. $331 \mathrm{f}$. Tese (Doutorado em Linguística) - Instituto de Estudos da Linguagem Universidade Estadual de Campinas, Campinas, 2002.

TONELI, P. A palavra prosódica em português brasileiro. $2014.335 \mathrm{f}$. Tese (Doutorado em Linguística) - Instituto de Estudos da Linguagem Universidade Estadual de Campinas, Campinas, 2014.

TRUCKENBRODT, H.; SÂNDALO, F.; ABAURRE, M. B. Elements of Brazilian Portuguese Intonation. Journal of Portuguese Linguistics, Lisboa, v. 8, n. 2, p. $75-114,2009$.

VIGÁRIO, M. Aspectos da Prosódia do Português Europeu: estruturas com advérbio de exclusão e negação frásica. Braga: CEHUM, 1998.

VIGÁRIO, M. The Prosodic Word in European Portuguese. Berlin: Mouton de Gruyter, 2003.

VIGÁRIO, M. O lugar do Grupo Clítico e da Palavra Prosódica Composta na hierarquia prosódica: uma nova proposta. In: ENCONTRO NACIONAL DA ASSOCIAÇÃO PORTUGUESA DE LINGUÍSTICA, 22., 2007, Lisboa. Actas... Lisboa: APL, 2007. p. 673-688. 